\title{
Classical complement activation induced by pregnancy: Implications for management of connective tissue diseases
}

\author{
N D Hopkinson, R J Powell
}

\begin{abstract}
Aims: To determine the efiect of pregnancy on C4d concentrations and to assess whether C4d remains a useful disease activity marker in the management of connective tissue diseases during pregnancy.

Methods: Plasma C3, C4, and C4d concentrations were measured in 83 women at various stages of normal pregnancy and compared with those in 80 nonpregnant controls.

Results: C3 concentrations in the pregnant women were significantly raised $(p=0.0001)$ and the $C 4$ concentrations were reduced $(p=0.0007)$, and accompanied by a significant increase in $\mathrm{C} 4 \mathrm{~d}$ $(p=0.0001)$. The $C 4 d: C 4$ ratio was higher in the pregnant women (p=0.0001).

Conclusions: Pregnancy induces activation of the classical complement pathway. C4d concentrations cannot be used to monitor disease activity in patients with connective tissue diseases during pregnancy.
\end{abstract}

Activation of the complement system is considered to be central to the inflammatory mechanisms in systemic lupus erythematosus (SLE). The measurement of complement breakdown products gives a quantitative assessment of such activation and has become established in some centres as a marker of disease activity. C3dg is a product of C3 activation by both the classical and the alternative pathway; $\mathrm{C} 4 \mathrm{~d}$ is a product of $\mathrm{C} 4$ activation by the classical pathway alone. Both have been shown to correlate with disease activity in SLE. ${ }^{12}$

The management of pregnant lupus patients entails careful monitoring. This can be even more problematical because certain laboratory variables are affected by normal pregnancy. A sustained increase in the erythrocyte sedimentation rate occurs during pregnancy, ${ }^{3}$ and increased concentrations of C3 and C4 have been shown, ${ }^{4}$ although this was significant only for $\mathrm{C} 3$ in serum samples assayed by rocket immunoelectrophoresis. ${ }^{5}$ Plasma C3 degradation products are not affected during the course of normal pregnancy ${ }^{6}$ and hence this variable remains a useful activity marker in pregnant patients with SLE.

The effect of pregnancy on C4d concentra- tions is unknown and therefore concentrations were measured in a group of pregnant women and normal controls to evaluate possible physiological changes.

\section{Methods}

Eighty three women (age range 16-42 years) at various stages of pregnancy were randomly requested to give an additional sample of blood treated with EDTA while attending for routine venepucture in an antenatal clinic. Patients with known complications of pregnancy and those receiving medication were excluded. EDTA plasma was separated within two hours of venepuncture and stored at $-186^{\circ} \mathrm{C}$ in vapour phase liquid nitrogen.

A control group comprised 80 subjects ( 47 men and 33 non-pregnant women, aged 16-84 years) attending a fracture clinic but who were otherwise well. The study was approved by the hospital ethical committee.

$\mathrm{C} 3$ and $\mathrm{C} 4$ concentrations were measured using a turbidometric assay on a centrifugal fast analyser. C4d concentration was quantified using rocket immunoelectrophoresis, based on the method of Nitsche et al, ${ }^{7}$ using an anti-human $\mathrm{C4}$ whole (Behring) where the faster rocket is C4d. After drying and staining, the rocket heights were measured and C4d values calculated from a standard curve. The C4d concentration of the standard (normal serum plus heat aggregated IgG, incubated at $37^{\circ} \mathrm{C}$ for one hour) was assigned an arbitary value of $100 \mathrm{Units} / \mathrm{ml}$. C4d:C4 ratios were calculated for both groups to give indices of complement activation independent of the initial concentration of $\mathrm{C4}^{2}{ }^{2}$

Results were expressed as mean (SD) and the results from groups compared using Student's $t$ test. Correlation coefficients were calculated using the Spearman's method.

\section{Results}

C3 concentrations were significantly higher in the pregnant women compared with controls $(1.10(0.16) \mathrm{g} / 1$ v $0.91(0.15) \mathrm{g} / \mathrm{l} ; \mathrm{p}=0.0001)$; $\mathrm{C} 4$ concentrations were significantly lower in the pregnant women $(0.24(0.08) \mathrm{g} / 1 \quad v \quad 0.28$ $(0.08) \mathrm{g} / \mathrm{l} ; \mathrm{p}=0.007)$. Both $\mathrm{C} 3$ and $\mathrm{C} 4$ concentrations, however, remained within the normal range for the laboratory.

The distribution of C4d values in the two groups is shown in figure 1 . The mean (SD) value in the normal group was $12.4(4.3)$ Units $/ \mathrm{ml}$ giving a reference range of 4-21 


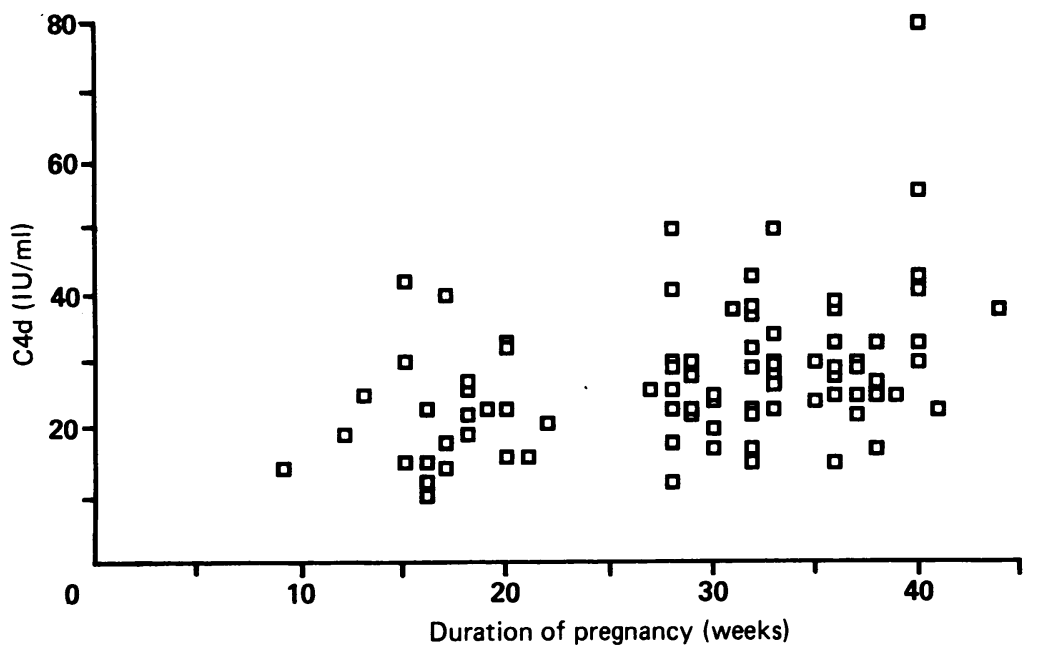

Figure 1 Distribution of $C 4 d$ concentrations in the two groups.

Units/ml (mean $2 \mathrm{SD}$ ). Mean C4d values in the pregnant women were $28 \cdot 1(10 \cdot 8)$ Units/ $\mathrm{ml}$, the difference between groups being significant $(t=12.3, \mathrm{p}=0.0001)$. Comparison of $\mathrm{C} 4 \mathrm{~d}$ concentrations among the pregnant women with normal women aged $16-42$ years only also showed a significant difference $(t=5 \cdot 2, \mathrm{p}=0.0001)$. Figure 2 shows C4d values in relation to the duration of pregnancy. Although there was a positive correlation between $\mathrm{C} 4$ and $\mathrm{C} 4 \mathrm{~d}$ concentrations in the pregnant women ( $R$ ho $=+0.35$ ), the mean C4d:C4 ratios were greater in pregnant women than in the normal group $(t=11.7$, $\mathrm{p}=0.0001$ ) confirming that complement activation was taking place.

\section{Discussion}

A significant degree of $\mathrm{C} 4$ activation in the plasma of healthy pregnant women is indicated by the increase in the $\mathrm{C} 4$ conversion product $\mathrm{C} 4 \mathrm{~d}$ and the higher fractional catabolic rate (C4d:C4). This $\mathrm{C} 4$ activation had occurred by the early part of the second trimester of pregnancy. The effect of increasing gestation on C4d concentrations in individual patients was not studied. Furthermore, patients were not followed to term so it is not known whether particularly high concentrations of $\mathrm{C} 4 \mathrm{~d}$ are associated with complications later on in pregnancy. Although

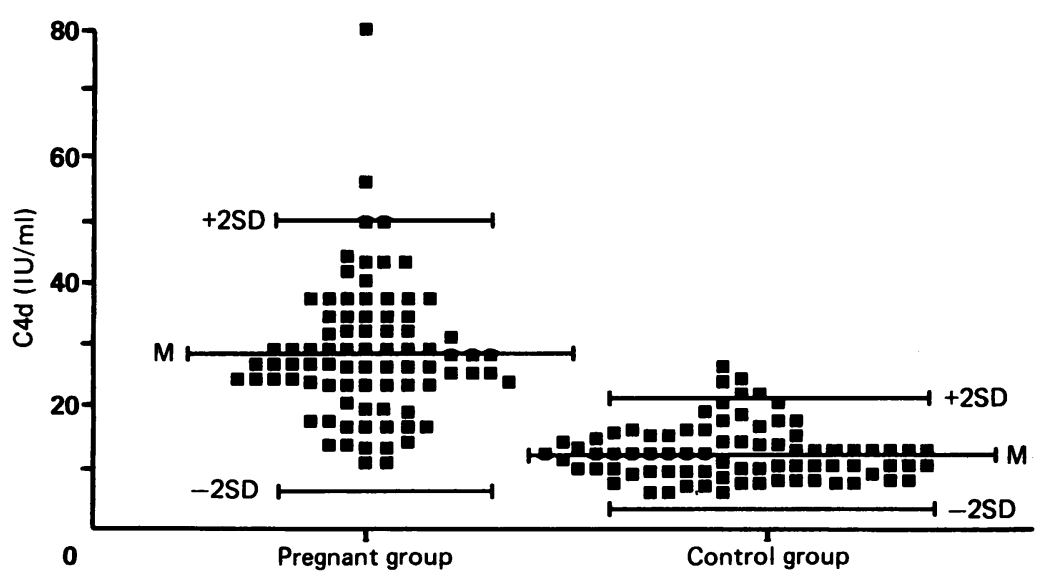

Figure 2 C4d concentrations in relation to the duration of pregnancy. the pregnant women were compared with a control group of men and women of a wider range, no effect of either gender or age on $\mathrm{C} 4 \mathrm{~d}$ concentrations was found in our laboratory (data not shown). Our findings are no different if women of childbearing age only are compared with the pregnant women. The rise in plasma C3 concentrations in normal pregnancy concurs with previous findings. ${ }^{45}$

Complement components have been identified in both mature and immature human placental tissue in association with stromal cells in areas of fibrinoid necrosis within the trophoblastic mantle and in the walls of fetal blood vessels. ${ }^{89}$ Thomson et $_{\text {al, }}{ }^{10}$ however failed to show clinically important complement activation in plasma collected from normal pregnancies as judged by normal concentrations of $\mathrm{Clq}, \mathrm{C} 4, \mathrm{C} 3$ and factor $\mathrm{B}$, and both $\mathrm{C} 3$ and factor $\mathrm{B}$ conversion products. Likewise, Jenkins et $a l^{6}$ failed to show changes in the $\mathrm{C} 3$ conversion product, $\mathrm{C} 3 \mathrm{dg}$, in normal pregnancies widely distributed in the second and third trimesters. Although trophoblastic basement membrane-bound C3d, accompanied by $\mathrm{C} 9$ but not by $\mathrm{Clq}$ or $\mathrm{C4}$, might suggest alternative pathway activation, $\mathrm{C4}$ has been noted in areas of intervillous fibrin deposition. ${ }^{11}$ This deposition of $\mathrm{C} 4$ suggests classical pathway activation and our findings of increased plasma C4d concentrations would further support classical pathway activation in addition to alternative pathway activation.

From a clinical standpoint, plasma C4d concentrations cannot be used as a marker of disease activity during pregnancy in patients with connective tissue diseases as pregnancy itself leads to $\mathrm{C4}$ activation, and measurements of $\mathrm{C4}$ must therefore be treated cautiously.

We thank Lupus UK for financial support.

1 Morrow WJW, Williams DJP, Ferec C, et al. The use of C3d as a means of monitoring clinical activity in systemic lupus erythematosus and rheumatoid arthritis. Ann Rheum Dis 1983;42:668-71.

2 Senaldi G, MaKinde VA, Vergani D, Isenberg DA. Activation of the fourth complement $(\mathrm{CA})$ reflects disease activity in systemic lupus erythematosus. Ann Rheum Dis 1988;47:913-17.

3 Taylor PV, Bird HA. Laboratory tests and problems of investigation. In: Scott JS, Bird MA, eds. Pregnancy, investigation. In: Scott JS, Bird MA, eds. Pregnancy, auto-immunity, and connective tissue
Oxford University Press, 1990:20.

4 Gallery ED, Raftos J, Gyory AZ, Wells JV. A prospective study of serum complement (C3 and CA) levels in normal pregnancy: Effect of the development of pregnancyassociated hypertension. Aust NZ J Med 1981;11:243-5.

5 Teisner B, Hau J, Tucker M, Lahood J, Gruckinekas J Circulating C3, C4 and $\mathrm{C} 3$ split products during normal pregnancy. Am J Rep Imomunol 1982;2:309-11.

6 Jenkins JS, Powell RJ. C3 degradation products (C3d) in normal pregnancy. J Clin Pathol 1987;40:1362-3.

7 Nitsche JF, Tucker ET, Sugimoto S, Vaughan JH, Curd JG. Rocket immunoelectrophoresis of CA and CAd. A simple Rocket immunoelectrophoresis of $\mathrm{CA}$ and CAd. A simple sensitive method for detecting complement
plasma. Am J Clin Pathol 1981;76:679-84.

8 Faulk WP, Jarret R, Keane M, Johnson PM, Boackle RJ. Immunological studies of human placentae: complement components in immature and mature chorinoic villi. Clin Exp Imomenol 1980;40:299-305.

9 McCormick JN, Faulk WP, Fox H, Fudenberg HH Immunohistological and elution studies of the human placenta. J Exp Med 1971;133:1-18.

10 Thomson NC, Stevenson RD, Behan WM, Sloan DP, Horne CHW. Immunological studies in pre-eclamptic toxacmia. Br Med J 1976;1:1307-9.

11 Faulk WP, Johnson PM. Immunological studies of human placentae: Identificaton and distribution of proteins in placentae: Identificaton and distribution of proteins in
mature chorionic villi. Clin Exp Immanol 1977;27:365-75. 